\title{
Axial Crushing and Energy Absorption of Empty and Foam Filled Jute-glass/ Epoxy Bi-tubes
}

\author{
Asad A. Khalid ${ }^{1, a}$ and Maziri Morsidi ${ }^{1}$ \\ ${ }^{1}$ Department of Mechanical Engineering, Faculty of Engineering, Universiti Teknologi Brunei, Brunei
}

\begin{abstract}
Experimental work on the axial crushing of empty and polyurethane foam filled bitubular composite cone-tube has been carried out. Hand lay-up method was used to fabricate the bi-tubes using woven roving glass, jute and hybrid jute-glass/epoxy materials. The tubes were of $56 \mathrm{~mm}$ diameter, and the cones top diameters were $65 \mathrm{~mm}$. Cone semi-apical angles of $5^{\circ}, 10^{\circ}, 15^{\circ}, 20^{\circ}$ and $25^{\circ}$ were examined. Height of $120 \mathrm{~mm}$ was maintained for all the fabricated specimens. Effects of material used, cone semi apical angle and foam filler on the load-displacement relation, maximum load, crush force efficiency, and the specific energy absorption and failure mode were investigated. Results show that the foam filler improved the progressive crushing process, increased the maximum load and the absorbed energy of the bitubes. The maximum crushing load and the specific energy absorption increased with increasing the cone semi apical angle up to $20^{\circ}$ for the empty bi-tubes and up to $25^{\circ}$ for the foam filled bi-tubes. Progressive failure mode with fiber and matrix cracking was observed at the top narrow side of the fractured bi-tubes as well as at the bottom surface of $20^{\circ}$ and $25^{\circ}$ cone semi-apical angle bi-tubes.
\end{abstract}

\section{Introduction}

Crashworthiness analysis is an important factor to design structures and to determine the capability of the structure to absorb energy and to protect vehicle occupants during collision event [1]. Fiberreinforced composite materials are used now in automotive industry to provide better crashworthiness with using lightweight materials [2]. The crush behaviour of composite structures offers distinct advantages for automotive applications and has been the subject of numerous investigations [3]. Several studies performed on composite structures like tubes [3-10] and cones [11-14] have been carried out to investigate the energy absorption capability and failure mechanism of these structures at different testing conditions. Researchers found that, high energy absorption can be obtained during the progressive crushing of composite tubes and cones under axial loading. In addition, researchers found that the stability, mode of failure and energy absorption of thin-walled tubular components can be improved by using foam fillers [10].

The mechanism by which the structure collapses has a direct influence on the energy absorption capability [11]. In this paper, a new foam filled bi-tubular arrangement is used for the aim of improving the crashworthiness under axial crushing. The main objectives of the present research are

${ }^{\text {a }}$ Corresponding author : asad.khalid@utb.edu.bn 
to investigate the crushing characteristics, specific energy absorption and failure mode of empty and foam filled bi-tubular cone-tube under axial compression loading. Also, the research aims to investigate the effect of cone-semi apical angle and material used on the performance of the bi-tubular arrangement.

\section{Experimental Work}

\subsection{Materials and Fabrication}

Composite cone and tube specimens were fabricated by hand lay-up method using woven roving jute and glass fibers with epoxy resin matrix. Cone and tube moulds were fabricated by using zinc coated mild steel sheets. Then the sheets were bent and welded to form the tube cone shape specimens. Plywood was inserted inside these hollow moulds for support purpose. A PVC circular cross-section sheets were cut with diameters equal to the top and bottom diameters of the cone and the tube and then fixed at the mould sides. The plywood was made in a way that can be easily extracted from these moulds after the completion of the fabrication process. Figure 1 shows the geometrical configuration of the fabricated bi-tubular cone-tube.

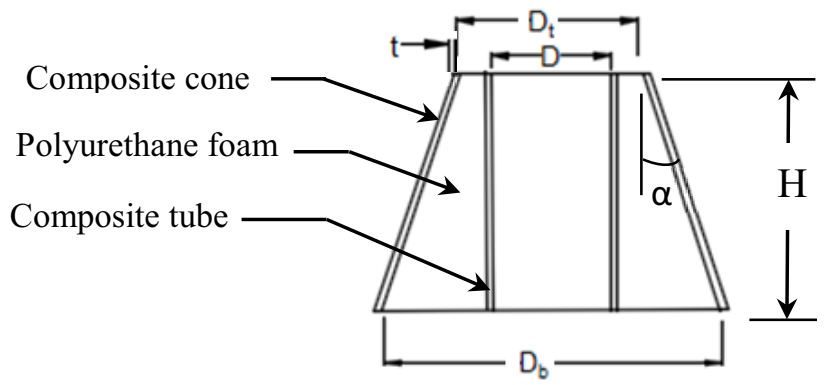

Figure 1. Geometrical configuration of the bi-tubular cone-tube

Where; $t$ is the wall thickness, $D$ is the tube diameter, $D_{t}$ and $D_{b}$ are respectively the top and bottom diameters of the cone. Table 1 shows the dimensions of the fabricated bi-tubular specimens. $(\alpha)$ is the cone semi-apical angle and $\mathrm{H}$ is the height of the specimen.

Table 1. Dimensions of the cone and tube arrangements

\begin{tabular}{|l|c|c|c|c|c|c|c|}
\hline \multirow{2}{*}{$\begin{array}{l}\text { Specimen } \\
\text { type }\end{array}$} & \multicolumn{4}{|c|}{ Outer cone } & \multicolumn{2}{|c|}{ Tube } & \multirow{2}{*}{$(\mathrm{H}), \mathrm{mm}$} \\
\cline { 3 - 8 } & $(\alpha), \mathrm{deg}$ & $\begin{array}{c}\left(\mathrm{D}_{\mathrm{t}}\right), \\
\mathrm{mm}\end{array}$ & $\left(\mathrm{D}_{\mathrm{b}}\right), \mathrm{mm}$ & $\begin{array}{c}\text { Number } \\
\text { of layers }\end{array}$ & $(\mathrm{D}), \mathrm{mm}$ & $\begin{array}{c}\text { Number } \\
\text { of layers }\end{array}$ & \\
\cline { 3 - 8 } $\begin{array}{l}\text { bi-tubular } \\
\text { cone-tube }\end{array}$ & 5 & 65.63 & 86.62 & 6 & 56 & 6 & 120 \\
\cline { 2 - 8 } & 10 & 65.63 & 107.95 & 6 & 56 & 6 & 120 \\
\cline { 2 - 8 } & 15 & 65.63 & 129.94 & 6 & 56 & 6 & 120 \\
\cline { 2 - 8 } & 20 & 65.63 & 152.98 & 6 & 56 & 6 & 120 \\
\hline
\end{tabular}

Tensile tests on composite specimens were performed to determine the mechanical properties of jute and glass/ epoxy materials. The properties of jute/epoxy specimens were $E_{11}=17.68 \mathrm{GN} / \mathrm{m}^{2}, \mathrm{G}_{12}=3.0$ $\mathrm{GN} / \mathrm{m}^{2}, \mathrm{G}_{23}=2.86 \mathrm{GN} / \mathrm{m}^{2}, v_{12}=0.29$ and $\rho=1600 \mathrm{~kg} / \mathrm{m}^{3}$. The properties of the glass/epoxy specimens were $\mathrm{E}_{11}=52.25 \mathrm{GN} / \mathrm{m}^{2}, \mathrm{G}_{12}=3.08 \mathrm{GN} / \mathrm{m}^{2}, \mathrm{G}_{23}=4.20 \mathrm{GN} / \mathrm{m}^{2}, v_{12}=0.35$ and $\rho=2100 \mathrm{~kg} / \mathrm{m}^{3}$. Where $\mathrm{E}_{11}$ is the modulus of elasticity in the longitudinal direction, $\mathrm{G}_{12}$ and $\mathrm{G}_{23}$ are the In-plane and out of plane modulus of rigidity, $v_{12}$ is the minor Poisson's ratio and $\rho$ is the density. For tubes with foam filler, polyurethane foam of $20 \mathrm{~kg} / \mathrm{m}^{3}$ density was used to fill the gap between the inner tube and the outer cone. 


\subsection{Testing Procedure.}

Constant slow speed compression testing was performed using a computer-controlled servo-hydraulic Instron machine type 5584 (Figure 2). The cross-head speed was adjusted at $4 \mathrm{~mm} / \mathrm{min}$. Composite bitubular cone tube specimens were axially crushed between two parallel steel flat platens, one is static and one is moving. The fixed platen was fitted with a load cell from which the load signal was taken directly to the computer. For each test, the crush load was plotted on the Y-axis and the crosshead displacement on the $\mathrm{X}$-axis.

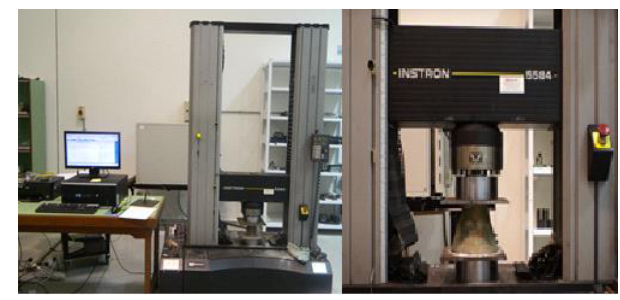

Figure 2. Instron machine type 5584 and test fixture.

\section{Results and Discussion}

\subsection{Crushing Characteristics}

Load-displacement graphs for the tested empty and foam filled bi-tubes are shown in Figure 3. Cone semi-apical angle of $5^{\circ}$ was used. The terms G, JG and J refer to the glass, jute-glass and jute materials respectively. The terms $\mathrm{E}$ and $\mathrm{F}$ refer to the empty and foam filled bi-tubes. It can be seen from this Figure that the load increased linearly till the initial failure load and then fluctuated with a slight increase till failure. The glass/ epoxy empty bi-tubes shown in Figure 3a supported load higher 31.28\% and $48.78 \%$ than the hybrid jute-glass and jute/epoxy empty bi-tubes respectively. The foam filled glass/ epoxy bi-tubes shown in Figure 3 b supported load higher $27.48 \%$ and $45.88 \%$ than the hybrid jute-glass and jute/epoxy foam filled bi-tubes respectively. The foam filled glass, jute-glass and jute/ epoxy bi-tubes supported load higher $16.69 \%, 21.05 \%$ and $21.15 \%$ than the empty glass, jute-glass and jute epoxy tubes respectively.

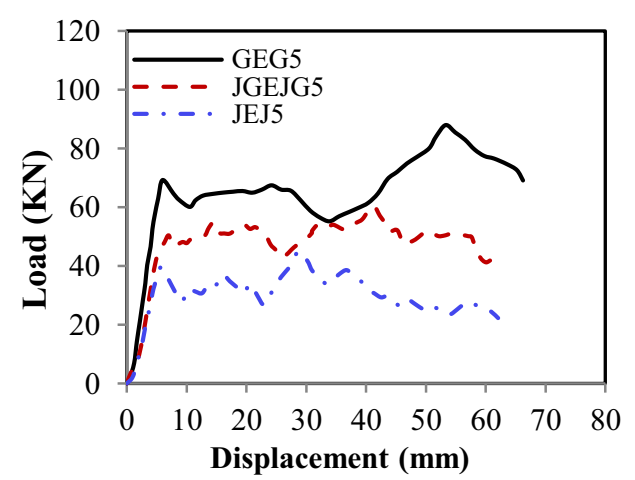

(a)

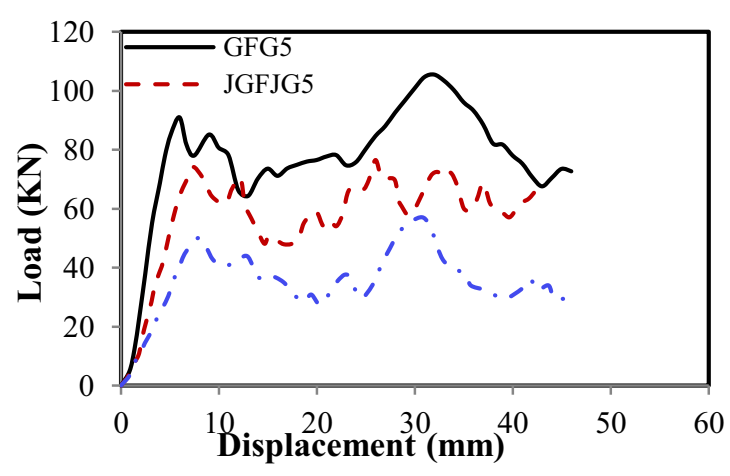

(b)

Figure 3. Load-displacement graphs for the (a) empty bi-tube and (b) foam filled bi-tube (Cone semi-apical angle $\left.=5^{\circ}\right)$

Figure 4 shows the load-displacement graphs of the empty and foam filled bi-tubes with semiapical cone angle of $25^{\circ}$. As shown, the foam filled glass, jute-glass and jute/ epoxy bi-tubes 
supported load higher respectively $37.97 \%, 38.98 \%$ and $46.40 \%$ than the empty glass, jute-glass and jute/ epoxy bi-tubes. The increase of cone semi apical angle from $5^{\circ}$ to $25^{\circ}$ increased the maximum load $25.25 \%, 32.20 \%$ and $33.40 \%$ respectively for the glass, jute-glass and jute/ epoxy foam filled bitubes. The increase in the load is attributed to the increase in the cross section area of the bi-tubes with the increase in the cone semi-apical angle and crush distance. With the increase in the cone semi apical angle from $5^{\circ}$ to $20^{\circ}$, the maximum load increased $11.72 \%, 19.52 \%$ and $18.70 \%$ respectively for the glass, jute-glass and jute/ epoxy empty bi-tubes. Further increase in the cone semi-apical angle of the empty bi-tubes, decreased the maximum.

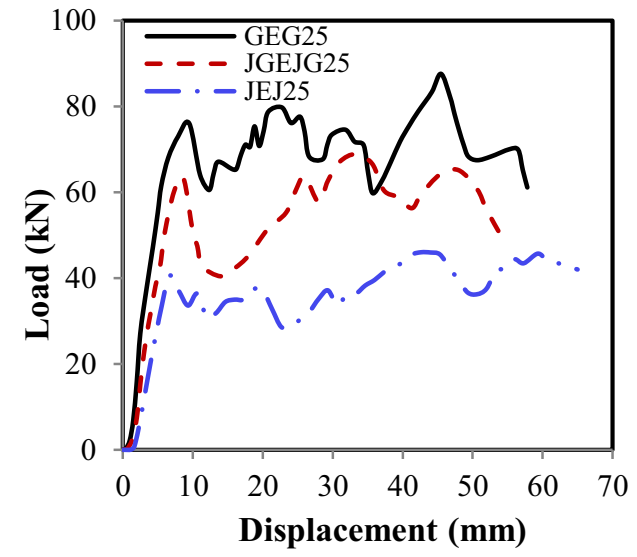

(a)

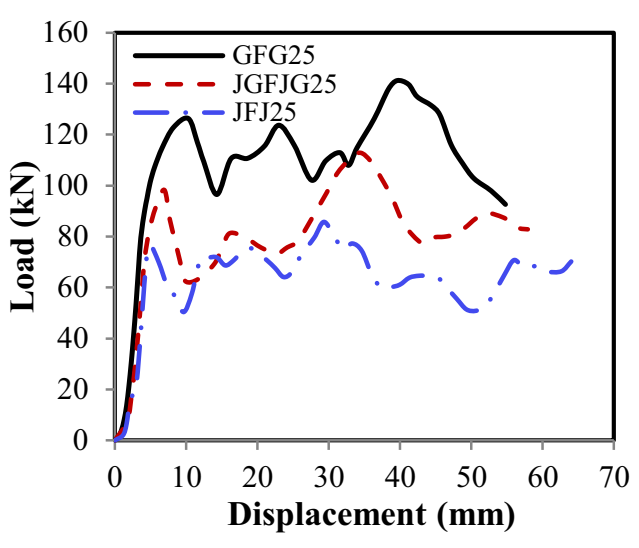

(b)

Figure 4. Load-displacement graphs for the (a) empty bi-tubes and (b) foam filled bi-tubes (cone semi-apical angle $\left.=25^{\circ}\right)$

Figure 5 shows effect of cone semi-apical angle on the maximum axial compression load of the empty and foam filled bi-tubes. Cone semi-apical angles of $5^{\circ}, 10^{\circ}, 15^{\circ}, 20^{\circ}$ and $25^{\circ}$ were examined. It can be seen that the maximum load increased with the increase in the cone semi-apical angle from $5^{\circ}$ to $20^{\circ}$ and from $5^{\circ}$ to $25^{\circ}$ for the empty and foam filled bi-tubes respectively. The foam filler provide stability to the bi-tubes to withstand the applied load. Maximum load values of $141.16 \mathrm{kN}, 112.84 \mathrm{kN}$ and $85.73 \mathrm{kN}$ respectively were obtained from the glass, jute-glass and jute/ epoxy foam filled bitubes of $25^{\circ}$ degree cone semi apical angle. The empty glass, jute-glass and jute/ epoxy bi-tubes supported maximum load values of $99.56 \mathrm{kN}, 75.05 \mathrm{kN}$ and $55.37 \mathrm{kN}$ respectively for the $20^{\circ}$ cone semi apical angle.

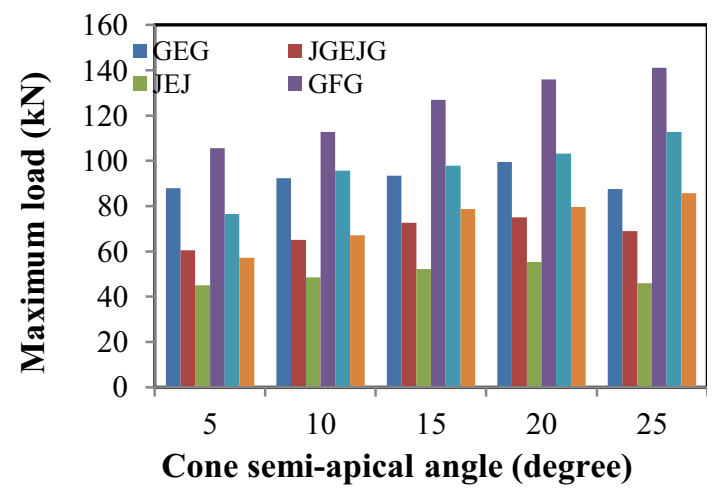

Figure 5. Maximum load versus cone semi-apical angle for the empty and foam filled bi-tubes

\subsection{Crush Force Efficiency}


The crush force efficiency (CFE) is important factors to measure the crush performance and to evaluate the crashworthiness of the energy absorber component. The CFE for the composite tubes under lateral loading is determined using the following equation $[2,5]$.

$$
C F E=\frac{F_{\text {mean }}}{F_{\text {max }}}
$$

Where $\mathrm{F}_{\text {mean }}$ and $\mathrm{F}_{\max }$ are the mean and maximum crush failure loads respectively.

Maximum absorption capacity is obtained when the crush force efficiency approach to unity cartographic damage [15]. On the other hand as the crush force efficiency decreases, the absorption capacity decreased resulted in a catastrophic failure [16].

Figure 6 shows the crush force efficiency of the axially crushed bi-tubes. As shown, crush force efficiency of the foam filled bi-tubes is significantly higher than the empty bi-tubes. Maximum crush force efficiency of $0.91,0.86$ and 0.84 were obtained by the foam filled glass, jute-glass and jute/ epoxy bi-tubes respectively. Maximum crush force efficiency of $0.82,0.79$ and 0.74 were obtained from the empty glass, jute-glass and jute/ epoxy bi-tubes respectively.

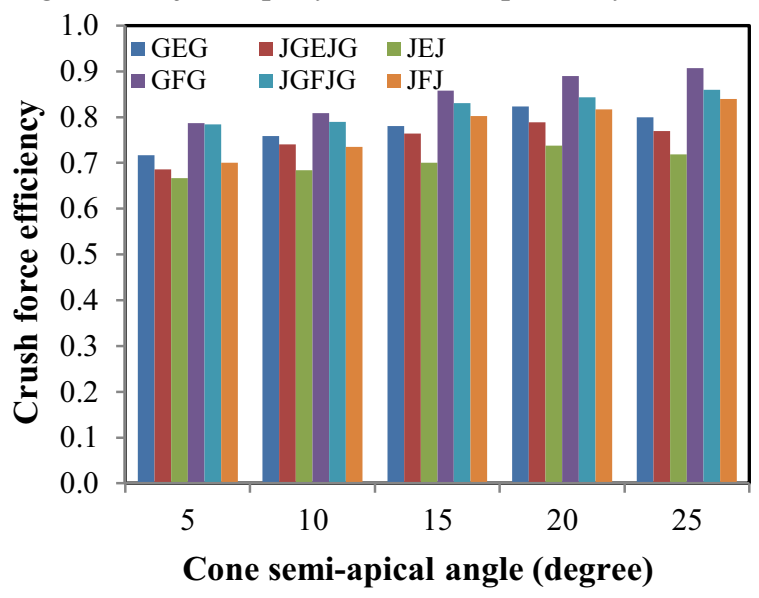

Figure 6. Crush force efficiency versus cone semi-apical angle for the empty and foam filled bi-tubes

\subsection{Specific Energy Absorption}

The specific energy absorption (SEA) is defined as the total absorbed energy $\left(E_{t}\right)$ per unit mass $(m)$ of the absorbed structure as in the following equation $[4,8,13]$ :

$$
S E A=\frac{E_{t}}{m}
$$

Where the total absorbed energy is the work done by the crushing force represented by the area under the axial force versus axial displacement curve and can be determined as follows $[4,8,13]$ :

$$
E_{t}=\int_{0}^{\delta_{\max }} F d \delta
$$

Where $F$ is the crush force in axial direction, and $\delta$ is the displacement in axial direction. The specific energy absorption of the axially crushed tubes is shown in Figure 7.

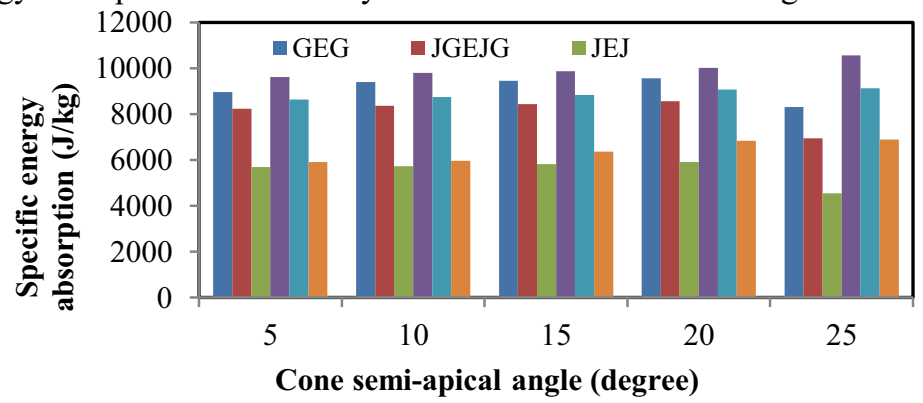

Figure 7. Specific Energy absorption of the axially crushed empty and foam filled bi-tubes 
It can be seen that, the specific energy absorption increased with the increase in the cone semi-apical angle. The energy absorbed by the foam filled bi-tubular cone-tubes is found higher than that obtained by the empty bi-tubes for all the cone semi-apical angles tested. Maximum specific energy absorption values of $1056 \mathrm{~J} / \mathrm{kg}, 9115 \mathrm{~J} / \mathrm{kg}$ and $6885 \mathrm{~J} / \mathrm{kg}$ were obtained by the glass, jute-glass and jute/epoxy foam filled bi-tubes respectively. Maximum specific energy absorption values of $9562 \mathrm{~J} / \mathrm{kg}, 8553 \mathrm{~J} / \mathrm{kg}$, and $5902 \mathrm{~J} / \mathrm{kg}$ were obtained by the empty bi-tubes of glass, jute-glass and jute/epoxy respectively

\subsection{Failure Mode}

Figure 8 shows the fractured specimens of empty and foam filled bi-tubular cone-tubes tested under axial compression load. The fracture initiated at the narrow upper end of the specimens at the region of the highest stress. It has been found that more fiber splitting obtained from the foam filled bi-tubes. The more fiber splitting provides stable crushing process with higher load to cause failure. Fiber break and matrix cracking were observed at the bottom end of the empty bi-tubular specimens of $20^{\circ}$ and $25^{\circ}$ cone semi apical angles. Samples of the fractured specimens are shown in Figure 9. The specimens were of $5^{\circ}$ cone semi-apical angle. It has been found that the foam filled bi-tubular specimens fractured by progressive crushing splaying mode.

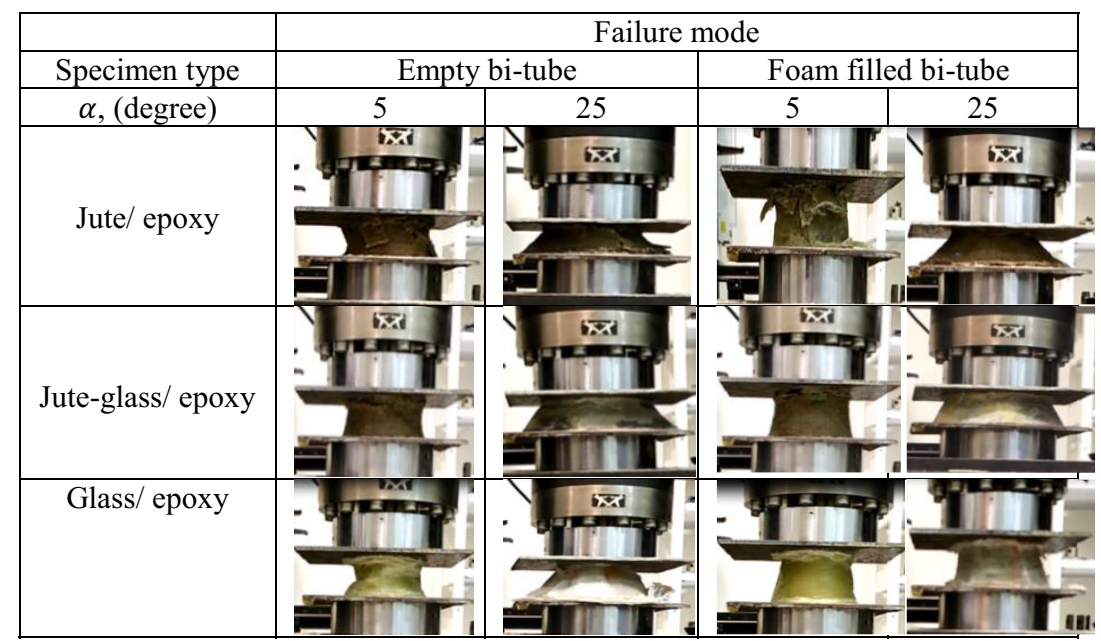

Figure 8. Failure mode of the bi-tubular cone-tube specimens

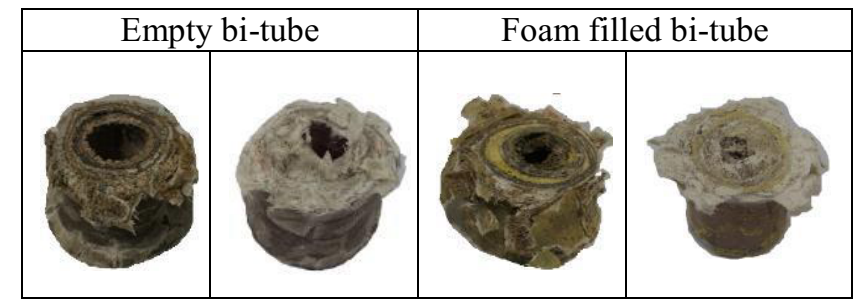

Figure 9. Comparison of the failure mode (cone semi-apical angle $=5^{\circ}$ )

\section{Conclusions}

The main conclusions that could be drawn from this investigation are:

1. The maximum load, crush force efficiency and the energy absorption increased with increasing cone semi-apical angle up to $20^{\circ}$ for the empty bi-tubes and up to $25^{\circ}$ for the foam filled bi-tubes. 
2. Maximum axial load of $141.16 \mathrm{kN}, 112.84 \mathrm{kN}$ and $85.73 \mathrm{kN}$ were obtained from the foam filled glass, Jute-glass and jute/ epoxy bi-tubes respectively with the cone semi-apical angle of $25^{\circ}$. The maximum loads obtained by the empty bi-tubes were $99.56 \mathrm{kN}, 75.05 \mathrm{kN}$ and $55.37 \mathrm{kN}$ respectively with the cone semi-apical angle of $20^{\circ}$.

3. The crush force efficiency of the foam filled bi-tubes is higher than the empty bi-tubes. Maximum crush force efficiency of $0.91,0.86$ and 0.84 were obtained from the foam filled glass, jute-glass and jute/ epoxy bi-tubes. The values were $0.82,0.79$ and 0.74 for the empty bi-tubes.

4. Maximum energy absorption of $10561 \mathrm{~J} / \mathrm{kg}, 9115 \mathrm{~J} / \mathrm{kg}$, and $6885 \mathrm{~J} / \mathrm{kg}$ were obtained from the foam filled glass, jute-glass and jute/ epoxy bi-tubes respectively with the cone semi-apical angle of $25^{\circ}$. The maximum energy absorbed by the empty bi-tubes were; $9562 \mathrm{~J} / \mathrm{kg}, 8553 \mathrm{~J} / \mathrm{kg}$, and $5902 \mathrm{~J} / \mathrm{kg}$ respectively with the cone semi-apical angle of $20^{\circ}$.

5. The bi-tubular specimens were fractured by progressive failure splaying mode with fiber and matrix cracking at the top narrow side of the specimens. Further cracks were noticed at the bottom surface of $20^{\circ}$ and $25^{\circ}$ cone semi-apical angle bi-tubes.

\section{References}

1. P.D. Bois, C.C. Chou, B.B. Fileta, T.B. Khalil,, A.I. King, Michigan: American Iron and Steel Institute (2004)

2. R. A. Eshkoor, S. A. Oshkovr, A. B. Sulong, R. Zulkifli, A. K. Ariffin, and C. H. Azhari, Mater. Des., 47, 248-257 (2013)

3. D. Hull, Compos. Sci. Technol., 40, 377-421 (1991)

4. R. A. Eshkoor, A. U. Ude, S. A. Oshkovr, A. B. Sulong, R. Zulkifli, A. K. Ariffin, and C. H. Azhari, Int. J. Impact Eng. 64, 53-61 (2014)

5. S. A. Oshkovr, R. A. Eshkoor, S. T. Taher, A. K. Ariffin, and C. H. Azhari, Compos. Struct. 94, 2337-2342 (2012)

6. A. Zuraida, A. A. Khalid, and A. F. Ismail, Mater. Des., 28, 71-77 (2007)

7. A. A. Khalid, Sahari B.B., Y.A. Khalid, Inst. Eng., 61 (1) 1-12 (2000)

8. M. Mirzaei, M. Shakeri, M. Sadighi, and H. Akbarshahi, Compos. Struct. 94, 1959-1966 (2012)

9. M. Haghi Kashani, H. Shahsavari Alavijeh, H. Akbarshahi, and M. Shakeri, Mater. Des., 51, 1095-1103 (2013)

10. L. Mirfendereski, M. Salimi, and S. Ziaei-Rad, Int. J. Mech. Sci. 50, 1042-1057 (2008)

11. A. A. Khalid, B. B. Sahari, and Y. A. Khalid, Compos. Sci. Technol. 62, 17-27 (2002)

12. M. Kathiresan, K. Manisekar, and V. Manikandan, Compos. Struct. 94, 3510-3519 (2012)

13. M. A. Guler, M. E. Cerit, B. Bayram, B. Gerçeker, and E. Karakaya, Int. J. Crashworthiness, 15 (4) 377-390 (2010)

14. M. Kathiresan, K. Manisekar, and V. Manikandan, Compos. Struct. 108, 584-599 (2014)

15. F. Tarlochan and S. Ramesh, Compos. Struct. 94(3) 904-916 (2012)

16. L. Guoxing and Y. Tongxi, England, Woodhead Publishing Limited, 1-23 (2003) 